\title{
Rumo ao desenvolvimento espacial sustentável? Explorando as implicações da nova bioeconomia no setor agroalimentar e na inovação regional
}

\section{Resumo}

O paradigma da bioeconomia pode ser descrito como o conjunto das atividades econômicas que captam o valor latente em processos biológicos e nos biorecursos renováveis, para produzir melhores condições de saúde, além de crescimento e desenvolvimento sustentáveis. Este artigo faz uma revisão crítica do impacto da bioeconomia emergente sobre o desenvolvimento rural. São descritas algumas das consequências do desenvolvimento rural bioeconômico, na esfera agroalimentar e da inovação regional baseada em uma definição específica - e, de nosso ponto de vista, fraca - de Modernização Ecológica. A questão central, então, é: quais são as bases conceituais, a força impulsora, as expressões empíricas e as implicações do desenvolvimento bioeconômico? Argumenta-se que, embora a bioeconomia faça duras cobranças em relação à sustentabilidade, também deixa lacunas, apresenta alguns efeitos secundários negativos, tanto ambientais como sociais, e corre o risco de ser uma economia parcial. Sustentamos, ainda, que a trajetória do desenvolvimento

\footnotetext{
1 Tradução de Regina Beatriz Vargas.

* Pesquisadora em desenvolvimento rural e regional, Grupo de Sociologia Rural, Universidade e Centro de Pesquisa de Wageningen, Holanda. E-mail: Lummina.Horlings@wur.nl

** Professor de Política e Planejamento Ambiental, Escola de Planejamento Urbano e Regional, Universidade de Cardiff. Diretor do Instituto de Pesquisa de Lugares Sustentáveis e Reitor de Pós-Graduação da Universidade de Cardiff E-mail: MarsdenTK@Cardiff.ac.uk
} 
ecoeconômico pode constituir uma boa alternativa para localidades particularmente vulneráveis que queiram aumentar sua resiliência.

Palavras-chave: Desenvolvimento sustentável. Modernização Ecológica. Bioeconomia. Ecoeconomia. Produção de alimentos.

\section{Introdução: o desafio de desenvolvimento sustentável para a ciência social}

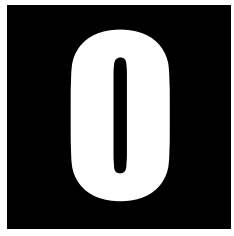

debate científico e governamental sobre desenvolvimento sustentável está entrando em uma nova fase. Durante muito tempo, as escolhas óbvias para as regiões foram trilhar o caminho do crescimento econômico e competir com outros lugares por trabalho e capital móveis, globais. Este desenvolvimento competitivo tem sido historicamente dominado por interesses econômicos tais como crescimento, renda e emprego (Armstrong e Taylor, 2000) - uma visão econômica ortodoxa, que segue sendo, em muitos lugares, o principal ponto de referência para as estratégias de desenvolvimento econômico. Também os conceitos de desenvolvimento regional que prevalecem no campo acadêmico (por ex. disparidades de crescimento regional e pólos de crescimento) provêm dos domínios da economia neoclássica (Pike et al., 2006).

Entretanto, desenvolvimento econômico e competitividade são, cada vez mais, considerados abordagens por demais limitadas para o tema do desenvolvimento regional, porque criam não só 'vencedores' como também 'perdedores'. Os 'vencedores' são geralmente encontrados em regióes ricas e valorizam os recursos naturais e os ativos locais. Os 'perdedores', por outro lado, tendem a concentrar-se em regiões vulneráveis, sofrendo o esgotamento de seus recursos naturais e ausência de ativos locais. Além disso, observam-se consequências sociais negativas que 
incluem questões relacionadas à injustiça ambiental, à polarização social e à exclusão social (Meynen e Doornbos, 2004). Em sua busca por uma abordagem alternativa, Wells e Bristow (2007) afirmam criticamente que:

Localidades e regiões não são entidades econômicas limitadas, cujo desempenho possa ser reduzido às suas firmas e ambiente microeconômico no qual operam. Entendê-las assim é criar um discurso reduzido sobre os caminhos para o bem estar regional, no qual os lugares ficam encerrados em círculos de comportamento competitivo cada vez mais intenso, em áreas de atividade estreitamente definidas, para sobreviver em um mundo globalizado (Well e Bristow, 2007, p. 207).

Tais noções se ajustam a uma consciência bem mais ampla de que, no longo prazo, os lugares deveriam adjudicar-se um desenvolvimento mais sustentável, para evitar concorrência desleal (OECD, 2006; Millennium Ecosystem Assessment, 2005). Desde a apresentação de Nosso Futuro em Comum (WCED, 1987), 'desenvolvimento sustentável' tornou-se um conceito chave em políticas relacionadas ao meio ambiente.

Também na área científica, intensificaram-se os esforços para promover e operacionalizar o novo campo da 'ciência da sustentabilidade'. Esta incorporou várias áreas das ciências, ganhando impulso diversificado a partir das ciências naturais, físicas e sociais. Ao mesmo tempo, a constante incorporação do ambientalismo às ciências sociais outorgou mais centralidade à operacionalização dos conceitos relacionados à sustentabilidade, tais como 'capacidade de suporte', pegada ecológica, técnicas de avaliação ambiental sustentável, equidade intergeracional e processos deliberativos e participativos. Desafios como mudanças climáticas e esgotamento de múltiplos recursos, ademais das demandas populacionais globais, irão criar rapidamente uma necessidade intelectual de novas explicações e de um paradigma científico que propugne novos (e verdadeiros) modelos de Modernização Ecológica (Horlings e Marsden, 2011). 
De que modo o desenvolvimento sustentável se manifestará nos lugares, não está claro. Não há um caminho único para a sustentabilidade. $\mathrm{Na}$ busca por novos modelos de desenvolvimento, diferentes paradigmas podem ser identificados: o paradigma da bioeconomia e o paradigma da ecoeconomia, por exemplo, cada qual sustentando modelos alternativos para o crescimento econômico e o desenvolvimento sustentável. Ambos os paradigmas têm seus próprios argumentos para a sustentabilidade, como veremos neste artigo, e podem ser analisados no contexto abrangente da teoria do desenvolvimento chamada Modernização Ecológica.

A Modernização Ecológica é empiricamente relevante em lugares que estão buscando formas de explorar seus recursos sem colocar em risco as perspectivas futuras. Além do mais, a ME é também um esforço teórico para a ciência social. Discutiremos, aqui, que a agenda ecologicamente modernizante tem sido interpretada de forma limitada em muitos países em desenvolvimento e que ela deveria estar fundada sobre uma base teórica mais diversificada (Buttel, 2000; Gibbs, 2000; Murphy, 2000).

O presente artigo faz uma revisão crítica do impacto da bioeconomia emergente sobre o desenvolvimento rural. São descritas algumas das consequências do desenvolvimento rural bioeconômico na esfera agroalimentar e da inovação regional que se baseiam em uma definição específica - e, de nosso ponto de vista, fraca - de Modernização Ecológica. A questão central, então, é: quais são as bases conceituais, a força impulsora, as expressões empíricas e as implicações do desenvolvimento bioeconômico?

Faremos a crítica desta trajetória de desenvolvimento argumentando que, embora a bioeconomia faça duras cobranças em relação à sustentabilidade, também deixa lacunas, apresenta alguns efeitos secundários negativos, tanto ambientais como sociais, e corre o risco de ser uma economia unilateral/parcial. Sustentamos que a trajetória do desenvolvimento ecoeconômico pode constituir uma boa alternativa para localidades 
particularmente vulneráveis que queiram aumentar sua resiliência. Isto se torna ainda mais relevante em um contexto de globalização e de crescentes fluxos internacionais de trabalho e capital.

Com o crescimento da bioeconomia em muitos locais, é oportuno, por diversas razões, que os cientistas sociais analisem suas consequências. Em primeiro lugar, a bioeconomia está relacionada a importantes debates envolvendo os tipos e estruturas de sustentabilidade que surgem nas políticas e nas práticas, bem como a capacidade desses modelos de enfrentar os principais desafios ambientais que aparecem. O imperativo do controle das emissões de carbono, em particular, tornou-se um novo conceito chave (Keil, 2007) e a gestão do carbono está sendo introduzida pelo estado como um modo de governança socioambiental (While et al., 2010). Os paradigmas da bioeconomia e da ecoeconomia suscitam questões relativas a quais vias - se estas houverem - se tornarão dominantes, de que modo e por que razão. Outras questões envolvem quem terá o controle dessas vias e sobre quais bases teóricas e conceituais tal controle se apoiará. Esta é uma questão pertinente em vista da tendência do conceito de sustentabilidade ser cooptado em modos de governança neoliberais (Drummond e Marsden, 1995; Hajer, 1995).

Em segundo lugar, existe um crescente debate envolvendo o impacto social e os efeitos dos avanços atuais da nova bioeconomia. Além do mais, ao passo que, do ponto de vista econômico, o modelo é apenas mais do mesmo - isto é, acumulação de capital a partir de trabalho intensivo e de processo de produção -, para alcançar este resultado, ele agora transforma a natureza 'a partir de dentro', o que suscita novas questões éticas, morais e sociais. Isto se torna ainda mais relevante, uma vez que a biotecnologia, por exemplo, é hoje uma grande impulsora e absorvedora de importantes gastos em $\mathrm{P} \& \mathrm{D}$, tanto pelo setor público como pelo privado (Carlson, 2007). 
Neste artigo, vamos construir e explicitar algumas definições conceituais da bioeconomia e da ecoeconomia (seção 2). Estas definições serão colocadas no contexto da teoria geral da modernização ecológica e de suas diversas - sejam fortes ou fracas - manifestações (seção 3). Além disso, revisando várias correntes da literatura das ciências sociais, iremos descrever e criticar as forças impulsoras da bioeconomia (seção 4) e as expressões e implicações da nova bioeconomia em relação ao setor agroalimentar (seção 5), bem como à inovação regional (seção 6), incluindo exemplos da América Latina. A seção 7 apresenta uma trajetória alternativa de desenvolvimento: a resiliência como uma estratégia ecoeconômica para localidades vulneráveis. Na última seção (seção 8), iremos extrair algumas conclusões e levantar questões para orientar novas pesquisas.

\section{Definições de bioeconomia e ecoeconomia}

\subsection{O paradigma da bioeconomia: uma definição}

O paradigma da bioeconomia pode ser descrito como o conjunto das atividades econômicas que captam o valor latente em processos biológicos e nos biorrecursos renováveis para produzir melhores condições de saúde, além de crescimento e desenvolvimento sustentáveis. Ao invés de um fenômeno local, de agregação de valor, este paradigma opera em níveis econômicos mais globais, corporativos.

Às vezes, usa-se também o termo 'economia biofundamentada', que lida de forma mais restrita com aplicações industriais: é uma economia que utiliza biorrecursos renováveis, bioprocessos eficientes e aglomerações ecoindustriais para produzir bioprodutos, empregos e renda sustentáveis (OCDE, 2006). Ela cobre e, efetivamente, combina áreas como medicina, nutrição, agricultura, biotecnologia industrial, meio-ambiente 
e segurança. E se expressa na produção (em geral controlada por grandes empresas) de biomassa e de biocombustíveis, bem como em outras atividades como biotecnologia, genômica, engenharia química e tecnologia enzimática (Juma e Konde, 2001; Comissão Europeia, 2005).

A OCDE considera que a bioeconomia poderá contribuir significativamente para a atividade econômica. A organização estima que, até 2030, o uso das biotecnologias contribuirá com até 35\% da produção industrial de químicos e de outros produtos que podem ser fabricados por meio de biotecnologia; com até $80 \%$ dos produtos farmacêuticos e de diagnóstico; e com cerca de 50\% da produção agrícola (OCDE, 2006).

\subsection{O paradigma da ecoeconomia: uma definição}

O modelo da ecoeconomia envolve o surgimento de redes complexas de empresas (muitas das quais pequenas e médias novas empresas) e atividades econômicas viáveis que se utilizam de recursos ecológicos de forma mais sustentável e ecologicamente eficiente (como por exemplo, novas empresas geradoras de energia renovável, empresas de agroturismo, de processamento e abastecimento de alimentos e empreendimentos sociais). O que é mais importante, elas não resultam em uma redução líquida dos recursos. Ao contrário, proporcionam benefícios cumulativos que agregam valor aos espaços rural e regional em termos tanto ecológicos quanto econômicos. Kitchen e Marsden (2009, p. 289) propõem uma definição [de ecoeconomia] que capta estas características:

a gestão social eficaz dos recursos ambientais (enquanto combinações dos capitais natural, social, econômico e territorial), de forma a integrar-se aos e aprimorar os ecossistemas local e regional, ao invés de desagregá-los e destruí-los. A ecoeconomia consiste, então, de 'redes', cumulativas e aninhadas, de empresas e atividades econômicas viáveis, que utilizam, de forma sustentável, os variados e distintos recursos ambientais de áreas rurais. Tais redes não resultam em uma diminuição 
líquida de recursos; antes, proporcionam benefícios líquidos e agregam valor ao ambiente e à comunidade.

A ecoeconomia expressa-se, por exemplo, em redes agroalimentares na forma de agricultura sustentável localmente incrustada e baseada no uso multifuncional da terra, em princípios agroecológicos e em novas redes de produção-consumo (Horlings e Marsden, 2011).

\section{Modernização Ecológica: a teoria geral}

\subsection{Modernização Ecológica como uma teoria do desenvolvimento}

O conceito teórico geral que funda tanto a bioeconomia como a ecoeconomia é o da Modernização Ecológica (ME). Tal conceito é central para ambos os paradigmas, porque tanto um como outro buscam e reivindicam o desenvolvimento sustentável defendendo diferentes trajetórias de desenvolvimento econômico.

A Modernização Ecológica é tanto um conceito teórico como um programa para política de desenvolvimento (Gibbs, 2000). A teoria da modernização ecológica emergiu de tentativas de lidar com os problemas identificados relativos à formulação e à implementação das primeiras políticas ambientais. Nos anos 1980, por exemplo, as práticas de controle da poluição no ponto de emissão (end-of-pipe), que apenas mudavam problemas relacionados ao processo industrial de um meio- ambiente para outro (Mol, 2000; Mol e Sonneveld, 2000).

As origens conceituais da modernização ecológica têm sido descritas, entre outros, por Anderson e Massa (2000), Christoff (1996), Gibbs (2000), Horlings e Marsden (2011) e Huttunen (2009). A noção de Modernização Ecológica surgiu de um debate ambiental na Alemanha, estando estreitamente relacionada a virtudes clássicas como Vorsorge (é melhor prevenir do 
que curar) e Vorsprung durch Technik (progresso via tecnologia). Ela compõe uma mensagem sobre as vantagens da inovação e pressupõe que é possível, através do desenvolvimento de novas tecnologias integradas, reduzir o consumo de matérias primas básicas, bem como as emissões de vários poluentes e, ao mesmo tempo, criar produtos inovadores e competitivos. Os principais instrumentos neste processo são a ciência e a inovação tecnológica (Anderson e Massa, 2000, p. 337). Assim, 'a estratégia da modernização ecológica visa, simultaneamente, a melhoria da eficiência ecológica e da eficiência econômica' (Jänicke, 1988, p. 23).

Pode-se dizer que tanto a bioeconomia como a ecoeconomia servem de exemplos da Modernização Ecológica. No entanto, cada uma delas representa uma distinta variante da ME; a bioeconomia segue o caminho de uma ME fraca ou limitada, ao passo que a ecoeconomia segue a linha de uma forte ME (Christoff, 1996; Dryzek, 1997; Gibbs, 2000).

\subsection{Modernização ecológica fraca ou limitada}

As versões 'fracas', segundo Dryzek, são Modernização Ecológica para engenheiros ou contadores, caracterizados como elites científicas, econômicas e políticas que tratam problemas ambientais formulando políticas a partir de uma visão tecnocrática e corporativista. Para Dryzek, as análises da ME 'fraca' ou 'limitada' tendem a estar restritas a Estados desenvolvidos e a corporações, que têm condições de consolidar suas vantagens econômicas sobre os Estados em desenvolvimento (Kitchen e Marsden, 2009).

Segundo Gibbs, a ME fraca ou limitada, frequentemente, deixa de levar em conta os processos sociais em curso, pois se apóia em uma abordagem tecnocrática e instrumental restrita, em lugar de uma integrativa e comunicativa (Gibbs, 2000, p.17). Este autor afirma que as interpretações limitadas da modernização ecológica também têm um fraco potencial para a integração de políticas e têm pouco a dizer sobre 
a forma de adaptação ou de mudança institucional exigidas para instituir o desenvolvimento sustentável. Além disso, não se enfrentam as barreiras à implementação da modernização ecológica, o que é visto como uma falha do estado, pela qual 'a política fica bloqueada a uma abordagem reativa e padronizada, mesmo que políticas mais proativas estejam disponíveis e ofereçam vantagens econômicas e ambientais' (Gouldson e Murphy, 1997, p. 80). A modernização ecológica tem pouco a dizer sobre as mudanças exigidas no nível do estado-nação e menos ainda em escala regional (Gibbs, 2000, p. 17):

este Estado facilitador irá propiciar a modernização ecológica através de relações de parceria entre governo e indústria, ainda que cooptando, quando necessário, movimentos de defesa do meio ambiente, ignorando questões de participação e reduzindo a sociedade em geral a meros consumidores a prover com informação suficiente para que façam escolhas informadas (embora, baseadas no mercado).

Nos casos em que a ME aborda questões de escala, Spaargaren e Mol (1992) criticam explicitamente os trabalhos de teóricos da contraprodutividade (como Commonor, Illich, Gorz e Bahro), por sua ênfase na necessidade de maior autonomia local e de rompimento dos laços com o mercado mundial e com as relações políticas como pré-requisitos para uma resposta à crise ecológica:

A intensificação das relações sociais internacionais e o crescente nível de distanciamento tempo-espaço nas sociedades modernas tornam menos plausível e realista a realização desses objetivos no contexto dos experimentos locais, considerados isentos das relações de poder e das forças de mercado que operam em âmbito mundial (Spaargaren e Mol, 1992, p.331).

A conexão entre bioeconomia e modernização ecológica (fraca) é relativamente clara. Vista como modernização ecológica (fraca), a bioecono- 
mia parece ser um caso de capitalismo que se utiliza da ciência ambiental na busca de vantagens econômicas; 'mais do mesmo', embora encoberto sob argumentos e referências ecológicas. Além disso, enquanto que, do ponto de vista ecológico, o modelo 'é mais do mesmo', ou seja, acumulação de capital a partir de processo de produção e de trabalho intensivos, ele agora transforma a natureza 'a partir de seu interior' (ver abaixo).

\subsection{Modernização ecológica forte}

A conexão entre ecoeconomia e modernização ecológica forte pode ser desenvolvida por associação com geografias rurais e desenvolvimento rural. Um componente importante do desenvolvimento rural é a multifuncionalidade. Como sugere McCarthy (2005), enquanto a modernização ecológica tem sido aplicada principalmente à industrialização (via ME fraca), seus elementos centrais se evidenciam na multifuncionalidade, conforme apontado por vários autores (por exemplo, Wilson, 2001; Evans et al, 2002; Marsden, 2004). Tais elementos centrais consistem na internalização de externalidades; na promoção da equidade intergeracional; na reflexividade entre atores da modernização ecológica; e num papel bem definido para o Estado.

Embora McCarthy (2006, p. 804) afirme que os espaços rurais foram e seguem sendo lugares primordiais, arquetípicos mesmo, do capitalismo, ele observa que as características das economias e das mercadorias alternativas tendem muitas vezes a entrecruzarem-se com as características dos espaços e produtos rurais: comunidades próximas e interativas; cadeias curtas de abastecimento; e imersão dos processos econômicos nas culturas e comunidades locais (Renting et al, 2003; Lamine, 2005; Kirwan, 2006).

Uma modernização ecológica 'forte' sugere processos reflexivos de aprendizagem social: tomada de decisão democrática, aberta; consideração das dimensões espaciais e de governança do desenvolvimento econô- 
mico e ambiental; uma abordagem equilibrada das questões econômicas, ambientais e sociais; e uma tendência a práticas deliberativas, discursivas e democráticas (Kitchen e Marsden, 2009). No entanto, para atingir tal condição seria necessária uma reestruturação das estruturas políticas capitalistas ou, como sugere Dryzek (1997, p. 65): [...] reconfiguração consciente e ação previdente de modo que o desenvolvimento econômico e a proteção ambiental possam caminhar lado a lado e reforçarem-se mutuamente.

O neoliberalismo demonstrou uma capacidade contumaz e duradoura de reinventar-se, acomodando-se às críticas e cooptando-as à sua lógica. Neste sentido, segue em aberto a questão de se é possível uma modernização ecológica forte ou um capitalismo sustentável. Como sustenta Hudson (2005), ao passo que existem fortes razões para se acreditar na improbabilidade de qualquer forma de ecocapitalismo, as chances de uma alternativa não capitalista sistêmica parecem no mínimo igualmente distantes. Isto o leva a concluir que:

o impossível pode, de fato, ser necessário e o necessário impossível na busca por se criarem práticas, fluxos e espaços econômicos sustentáveis - pelo menos, na ausência de uma reavaliação radical de conceitos como 'a economia', 'produtividade' e 'desenvolvimento' e de consequentes mudanças em práticas relacionadas a uma transformação fundamental nas relações sociais que dominam a economia e definem práticas legítimas (Hudson, 2005, p. 250).

É preciso nada menos que uma solução 'total' para as contradições e crises do capitalismo, por meio de um conjunto de relações sociais que produzam um acordo econômico, político e ambiental mais equitativo e sustentável (Harvey, 2000). 


\section{Forças impulsoras do desenvolvimento bioeconômico}

Como tratado acima, sustentamos que a bioeconomia é um exemplo de modernização ecológica fraca, mas que tem fortes implicações. Podemos identificar diversas forças impulsoras que estão promovendo a biotecnologia em alguns lugares - criação de 'espaços de terceira natureza', inovação técnica e ecologia industrial -, as quais são descritas abaixo.

\subsection{Criação de 'espaços de terceira natureza'}

Retrocedendo teoricamente, se poderia dizer que a bioeconomia é representativa dos processos capitalistas descritos por Smith (1984), através dos quais a natureza é transformada pelo capital em 'segunda' natureza ou natureza social. A segunda natureza está submetida às relações humanas, que resultaram em sua mercantilização e exploração econômica através do processo capitalista (Smith, 1984, p. 55). Contudo, sugerimos que o paradigma bioeconômico vai muito além e começa a estabelecer a 'terceira natureza'. Os processos bioeconômicos têm potencial para, e em alguns casos já conseguiram, transformar a natureza em um nível genético, fundamental. Para o paradigma bioeconômico, não é suficiente apenas mercantilizar a natureza enquanto 'primeira natureza'. Ao contrário, é preciso agora transformar os processos biológicos e reprodutivos da própria natureza, de modo a que esta obedeça a diferentes regras e parâmetros temporais e espaciais, e que reduza algumas das prévias externalidades ambientais. Esta é uma nova forma de controle corporativo e de patenteamento sobre as 'indisciplinadas' primeira e segunda naturezas; uma forma que, ao mesmo tempo, abre novos espaços de 'terceira natureza' a uma nova acumulação seletiva e criação de riqueza (Kitchen e Marsden, sob revisão).

Portanto, o cerne do paradigma bioeconômico é buscar um caminho para um 'desenvolvimento sustentável' mais amplo, através da 
inovação científica, especialmente a manipulação genética, em áreas como de alimentos, combustíveis, energia e medicamentos. Este processo exige um significativo grau de manipulação e de controle dos processos reprodutivos naturais (de plantas e de animais) assim como um controle amplamente privatizado das técnicas e práticas que os possibilitam. Além disso, ele reconstitui as diferentes demandas dos fatores tradicionais de produção (terra, trabalho e capital), ao despojar ainda mais a produção de alimentos de suas características naturais distintivas, que por tanto tempo obstruíram a plena penetração capitalista no setor agroalimentar (Kautsky, 1899, Mann e Dickenson, 1978).

A bioeconomia, então, parece buscar separar-se da natureza e ter um maior controle sobre a mesma, através da ciência. Pode ser que esta tentação seja grande demais para que cientistas e o industrialismo capitalista - e mesmo os consumidores - consigam resistir. Como observa Carlson (2007, p. 116):

O trabalho em tecnologias biológicas continuará desenvolvendo-se, porque a possibilidade de melhores e mais frequentes colheitas, de abundância de biocombustíveis, e de melhores condições da saúde humana através de novas vacinas e da reposição de tecidos é cientifica, política e economicamente muito tentadora para que os seres humanos possam resistir.

\subsection{Inovação técnica}

Uma segunda importante força impulsora da bioeconomia é a inovação técnica. A questão, aqui, é como funciona a inovação e como ela contribui para a transição da sociedade. Neste ponto, são úteis a teoria da transição (Rotmans et al, 2001a/b) e a perspectiva de múltiplos níveis de inovações/transições desenvolvida por Geels (Geels, 2004; Geels et al., 2008). A teoria da transição descreve como a busca do desenvolvimento 
sustentável exige mudanças radicais no nível de regime - chamado de transições - e sustenta que, embora estas não possam ser controladas, podem, em alguma medida, ser governadas pela sociedade (Rotmans et al, 2001b). Os regimes representam formas institucionalizadas de colaboração horizontal. Quanto mais os nichos de inovação forem capazes de equilibrar ou de levar em conta os desenvolvimentos emergentes da paisagem, tanto mais eles terão sucesso em derrubar os regimes estabelecidos em favor de novos, produzindo, assim, a verdadeira transição. A abordagem da inovação/transição é relevante, aqui, em razão do modo como trata a interação entre o avanço dos nichos e as condições institucionais mais amplas, equilibrando, assim, os aspectos processo/ator e instituição/estrutura. Tal abordagem evita formas reducionistas de análise das dinâmicas dos processos de inovação - tanto as centradas no ator como as centradas na estrutura -, concentrando-se, em vez disso, em como ambos os níveis interagem, seja no sentido positivo ou no negativo.

\subsection{Ecologia industrial}

Outra importante força impulsora da bioeconomia é a ecologia industrial, um 'casamento entre a indústria e a biologia'. A ecologia industrial está baseada nas tecnologias biológicas que se desenvolveram de modo muito rápido, especialmente a partir do início deste século. Ela oferece uma via para a autonomia energética e para uma 'economia verde' aprimorada (Jordan et al., 2007, p. 1570). Esta é uma iniciativa orientada à empresa, que visa reduzir o impacto da empresa no ambiente promovendo a ecoeficiência do tipo 'ganha-ganha', isto é, que as economias ambientais (por exemplo, a redução do consumo de materiais e de energia) possam também gerar economias de custos (Deutz e Gibbs, 2008).

Podem-se identificar duas características principais da ecologia industrial. A primeira é o desacoplamento em curso entre os sistemas de 
produção e o ambiente natural. Um exemplo é a utilização, em sistemas biológicos sintéticos, de componentes padronizados, com funcionalidades definidas e, portanto, previsíveis, os quais possibilitam projeto e montagem com base tão somente em especificações (Carlson, 2007). Aplicado à biologia, este desacoplamento fornece um modo de produzir um novo projeto, que é claramente distinto daquele de modificação ou combinação de processos que define evolução.

Uma segunda característica é a ecoeficiência. O Conselho Mundial de Empresas para o Desenvolvimento Sustentável (World Business Council for Sustainable Development) tem descrito ecoeficiência como uma estratégia para o aprimoramento da competitividade das empresas por meio de melhorias ambientais: criação de mais produtos e serviços com o uso de menos recursos, e redução de resíduos e de poluição (Nilsson et al, 2009, p. 4). A tendência em direção à ecoeficiência tem estimulado o agrupamento de empresas altamente eficientes em torno de ciclos fechados de energia, de água e de resíduos. A eficiência bioeconômica está se desenvolvendo paralelamente à aceleração dos ciclos dos produtos (Nilsson et al (2009). Embora os ciclos dos produtos na engenharia biológica sejam normalmente mais lentos (Carlson, 2007, p. 111), a modificação genética de plantas proporciona a alteração das culturas de modo muito mais rápido do que as técnicas tradicionais. Em outras palavras, a bioeconomia estrutura as noções de tempo, de velocidade dos ciclos de vida.

Como o paradigma da bioeconomia atua na prática? Que exemplos se têm do desenvolvimento econômico? Na próxima seção, faremos uma descrição e revisão crítica das implicações na esfera agroalimentar e na inovação regional. 


\section{A bioeconomia no setor agroalimentar}

\subsection{Avanços na bioeconomia}

O setor agroalimentar tem sido fortemente influenciado, nas últimas décadas, pelos avanços da bioeconomia, os quais podem ser caracterizados pela ênfase no desenvolvimento de tecnologias, na regulação governamental e em serviços de extensão. Podemos identificar diversas arenas para o desdobramento da bioeconomia no setor agroalimentar:

A melhoria da eficiência através de técnicas tradicionais de cultivo e reprodução;

A manipulação de condições ambientais, tais como da fertilidade do solo (com fertilizantes), da terra (drenagem, irrigação, mudanças no sistema de registro e de divisão de terras) e relações ecológicas (gestão química de pragas e de ervas daninhas);

A desvinculação de produtos agrícolas de seus ambientes [naturais] (estufas e criação intensiva de animais de granja), a desvinculação entre produção e processamento em agronegócios, e a desvinculação entre a gestão da terra e a propriedade dos recursos (tais como de sementes e patentes);

A construção (engenharia) biológica de características intrínsecas específicas da própria natureza e a industrialização de produtos alimentícios, baseadas na redução de produtos primários a segmentos padronizados e componíveis. A biotecnologia conduziu a novas espécies, novos impactos ecológicos e à produção industrial de produtos alimentícios como a carne artificial, por exemplo.

A ecologia industrial criou condições para a criação de muitos novos bioprodutos. O uso de produtos primários de base biológica para todos os tipos de aplicações recebeu forte apoio governamental em alguns países. 
A ciência biológica tem crescente influência sobre a produção agrícola na forma de análise genética e genômica, tecnologia de marcadores, modificação genética e análise de fenótipo.

\subsection{Biotecnologia}

A importância da biotecnologia cresce rapidamente. Genes ou combinação de genes que afetam a produção das plantações podem ser facilmente identificados com o uso da genômica. Nas estratégias de melhoramento genético, estes genes podem ser alvo de programas de cultivo ou podem ser transferidos para a lavoura através de manipulação genética (para uma descrição geral ver The Royal Society, 2009).

A biotecnologia é recomendada em razão dos benefícios que proporciona para a melhoria das lavouras, a proteção contra pragas, ervas daninhas e outras doenças, e o controle genético das perdas pós-colheita. A grande promessa das estratégias de manipulação genética é a de que elas também podem melhorar a resistência a doenças, os nutrientes minerais do plantio e aprimorar a qualidade nutricional das culturas em locais onde exista deficiência alimentar (The Royal Society, 2009).

No Brasil, a promulgação pelo Congresso brasileiro de uma nova lei sobre biossegurança, sancionada pelo Presidente da República, em 2005, superou o principal obstáculo ao desenvolvimento de atividades relacionadas à moderna biotecnologia no país. A comunidade científica ganhou reconhecimento mundial pelos resultados obtidos com a genômica e a engenharia genética (Da Silveira e De Carvalho Borges, 2005, p. 3).

A aplicação das técnicas de modificação genética a plantas cultivadas tem sido controversa. No Brasil, EUA, Argentina, Índia e Canadá as culturas transgênicas são amplamente cultivadas (125 milhões de hectares), enquanto na Europa e na África (com exceção da África do Sul), elas em geral estão ausentes (ISAAA, 2008). Os críticos acreditam que tais 
novas biotecnologias não cumprirão suas promessas e que irão afetar a autonomia e o poder das comunidades de agricultores (ver por exemplo, Altier e Rosset, 1999). Uma das principais críticas à biotecnologia é que ela pode criar novas vulnerabilidades - problemas ambientais e riscos que ainda não podemos prever: [a]o descerrar os segredos do genoma, a biotecnologia nos permitiu eludir alguns problemas ambientais e de recursos, mas pode também criar outros completamente novos. (Anex, 2004, p. 2).

\subsection{Produção de biocombustíveis}

A inovação no processamento industrial da produção agrícola abriu caminho para a produção em larga escala de biomassa. As políticas e a pesquisa e desenvolvimento ( $P \& D$ ) têm privilegiado a maximização da produção de biomassa e a otimização de seu uso, com muito menos ênfase na avaliação de seu desempenho econômico, social e ambiental. Este desequilíbrio leva muitos grupos de interesse a se oporem ao crescimento desta bioeconomia agrícola (Jordan et al, 2007, p. 1570).

A produção de biocombustível é ainda um setor bioeconômico em desenvolvimento, especialmente em países como o Brasil. Como resposta à crise do petróleo, este país escolheu um caminho alternativo para o suprimento de energia. O Brasil esteve entre os primeiros países que almejaram tornar-se independentes das importações de petróleo e lançou, em 1975, o programa Proalcool que promove a substituição de combustíveis fósseis por biocombustíveis no setor de transportes (Mayer, 2009).

A tendência de uso de matérias primas de origem vegetal na produção industrial pode ter impactos sociais e ambientais complexos. O crescente comprometimento da agricultura como fonte de biocombustíveis entrará em conflito com a necessária ampliação da produção de alimentos no futuro e, provavelmente, terá impactos ambientais negativos na qualidade da água e do ar (Anex, 2004, p. 2). A concorrência pela 
terra também tem crescido em decorrência das culturas destinadas a produção de biocombustíveis (Mol, 2007). O resultado disso vem sendo nova apropriação internacional de terras, com países em industrialização como a China, Japão, Coréia do Sul e Arábia Saudita buscando terras e recursos agrícolas em partes da África. Vemos esta concorrência por terras crescer particularmente no setor de produção de biocombustíveis.

A decisão de como abastecer nosso carro pode ter impactos na subsistência de famílias pobres em outra parte do mundo completamente diferente. Desmatar terras em favor de cultivos que produzem energia pode aumentar as emissões causadoras do efeito estufa relativas ao uso contínuo de combustíveis derivados de petróleo (Börjesson, 2009). A passagem para cultivos destinados à produção de energia, mesmo em terras aráveis já existentes, pode provocar efeitos de deslocamento com impactos similares, embora indiretos, sobre as emissões. Sem salvaguardas adequadas, a expansão dos biocombustíveis pode afetar negativamente a biodiversidade e os recursos hídricos (Nilsson et al, 2009, p. 22). A concorrência por matérias primas ou por terra pode provocar aumento de preços dos alimentos (RFA, 2008). Ros e colegas (2010, p. 3) fornecem um panorama dos impactos diretos e indiretos da produção de bioenergia e afirmam que ela tem potencial para reduzir a emissão de gases de efeito estufa (GEE), mas que os efeitos indiretos, tais como modificações indiretas no uso da terra que levam à intensificação da agricultura e de emissões de GEE, podem eliminar parcial ou completamente este benefício.

Um avanço relativamente recente é a produção de combustíveis sintéticos a partir de micróbios produzidos por empresas como a Amyris Biotechnologies. Como resultado desses processos, quantidades crescentes da produção total dos compostos economicamente importantes serão, em breve, 'miniaturizadas' dentro de sistemas biológicos, internalizadas em organismos unicelulares (e eventualmente pluricelulares). 


\subsection{Ecoeficiência na produção agrícola}

A ecologia industrial conduziu a sistemas inovadores de agricultura, com mais ciclos fechados de energia, de minerais e de resíduos, também chamados parques agrícolas. Os parques agrícolas comportam culturas vegetais e criação de animais altamente produtivas, bem como processamento de caráter industrial, tudo combinado com a introdução de elevados níveis de conhecimento e tecnologia; os ciclos de água, minerais e gases são eficientemente fechados e o uso de energia fóssil é minimizado, particularmente através do processamento de vários resíduos e subprodutos dos fluxos de produção. Um parque agrícola pode, portanto, ser visto como a aplicação da ecologia industrial ao setor agrícola (Smeets, 2009). O conceito de parque agrícola está se desenvolvendo em várias partes do mundo; alguns projetos estão sendo desenvolvidos, por exemplo, na China (Parque de Greenport Sjanghai e o Parque WAZ-Holland, na província de Jiangsu) e na Índia (IFFCO-Greenport Nellore) (Smeets, 2009). Estes novos sistemas intensivos de agricultura suscitam novas questões; por exemplo, sobre sua 'adequação' à paisagem e sobre como um contato mais direto com os consumidores pode ser realizado. Os 'mega estábulos' também têm levantado consideráveis protestos da sociedade, como por exemplo, nos EUA e na Holanda.

5.5 Algumas dimensões perdidas da modernização ecológica fraca no setor agroalimentar

Os avanços da bioeconomia no setor agroalimentar podem ter levado a alguma redução nos problemas ambientais. No entanto, efeitos secundários negativos também foram observados. Estes efeitos ilustram a exclusão ou, no melhor dos casos, a subestimação de dimensões mais amplas e muito mais diversas da agricultura no projeto da modernização ecológica fraca - as dimensões social, cultural, política e espacial. Po- 
demos mencionar a falta de pelo menos quatro dimensões (Horlings e Marsden, 2011).

Socialmente, temos observado uma grande redução dos empregos na agricultura e uma perda de autonomia pelos agricultores, com sua maior dependência em relação a mercados globais autoregulados, aos varejistas, à pesquisa e às políticas (Van der Ploeg, 1991; Horlings, 1996). Produtores de insumos básicos, no final da cadeia, têm a responsabilidade pela qualidade dos produtos, mas são excluídos dos mercados geralmente mais lucrativos de alimentos com valor agregado destinados ao varejo. Para aqueles que conseguem ingressar nestes mercados, o grau de controle informal exercido sobre suas operações restringe sobremaneira seu 'espaço de manobra' (Marsden, 2004, p. 137). A modernização ecológica fraca pode, assim, levar à perda de autonomia no nível local.

Culturalmente, 'o ambiente' é reduzido a uma série de interesses fragmentados, ou 'encaixotados', sobre insumos, resíduos e emissões poluidoras. Como as necessidades culturais e os valores não antropocêntricos não podem ser expressos em termos monetários, tendem a marginalizar-se ou não ser levados em consideração (Christoff, 1996).

Politicamente, na agricultura, tornou-se dominante no setor agroalimentar um 'modo higiênico de regulação' através da proliferação de instrumentos e garantias ambientais remotas e burocráticas. Formas privadas e públicas de regulação levaram a uma esquematização que gera novas barreiras regulatórias à entrada no mercado para muitos pequenos agricultores e fabricantes. Propriedades rurais (e agricultores) têm suportado a pior parte desta estratégia científica de gestão de risco (ver Marsden, 2010).

Espacialmente, a produção agrícola intensiva foi fragmentada e desvinculada de seu espaço e lugar, o que fica evidente no modo flexível de produção, no transporte internacional de alimentos e na desconstrução dos alimentos em diferentes componentes alimentares de valor agregado. 
Isto confere ao produtor e ao processador industriais o poder de intercambiar recursos internacionalmente, tornando os agricultores mais vulneráveis aos mercados globais (Van der Ploeg, 1992).

Exemplos de modernização fraca podem ser testemunhados no contexto da modernização rural na América Latina. Por exemplo, o desenvolvimento rural baseado no conceito de Revolução Verde mudou a paisagem social e ecológica no Brasil, especialmente a partir do final da década de 1960. A expansão da pecuária extensiva e a mecanização da agricultura foram grandes forças impulsoras neste processo de transformação. No Centro-Oeste, uma das últimas regiões de fronteira no Brasil, grandes extensões de terras de planície foram desmatadas para plantio de pastagens e de cultivos comerciais. Após o deslocamento dos povos indígenas, durante os primeiros confrontos com os exploradores portugueses, no século XVIII, assistiu-se à expropriação das terras dos antigos pequenos agricultores que se haviam instalado na região, dois séculos atrás. As comunidades rurais continuaram marginalizadas e sem poder, em face das pressões e impacto dos recentes avanços no agronegócio e na pecuária. O sistema já não é sustentável. Em razão da expansão capitalista e da prevalência de condições de insegurança em relação à ocupação da terra, de falta de acesso a recursos básicos e de alta pressão populacional sobre recursos escassos, os camponeses tiveram de intensificar a produção. Este fato teve sérias consequências negativas, de natureza social, econômica e ambiental, nas comunidades rurais tradicionais (Gutberlet, 1999).

Até aqui, focamos a atenção no desenvolvimento econômico na esfera agroalimentar. Nas próximas seções, vamos ampliar nosso horizonte para examinar o contexto alargado da inovação regional. 


\section{A bioeconomia na inovação regional}

As idéias sobre desenvolvimento econômico regional nos últimos anos têm sido dominadas pelos mantras da globalização e da competitividade. Competitividade é normalmente definida em termos muito amplos e se refere à 'atratividade' de uma região, ou à sua capacidade de competir com outros lugares pelo capital transnacional e trabalho especializado, em um mundo crescentemente globalizado. Nestes termos, fornece um conjunto relativamente explícito de mensagens àqueles que concebem as estratégias e políticas regionais de desenvolvimento econômico, a saber: um imperativo de privilegiar a criação do tipo adequado de ambiente empresarial para a atração e retenção de agrupamentos de firmas inovadoras, de trabalho qualificado ou 'criativo', de investimento transnacional e de subsídios e fundos governamentais centrais e supranacionais. Um resultado que não surpreende é o de que as estratégias de desenvolvimento econômico regional estão repletas da linguagem do vencer, do ganhar alguma vantagem competitiva sobre as demais regiões, e da comparação do desempenho competitivo em relação a 'rivais', por meio de indicadores e classificações (Bristow, 2009).

A competitividade tornou-se, de fato, uma 'lei natural' para o desenvolvimento econômico e para as políticas e a busca por empresas globalmente competitivas, o imperativo resultante. As regiões tentam promover a competitividade regional através das aglomerações industriais. Novas aglomerações de empreendimentos 'verdes' estão surgindo, envolvendo empresas de biotecnologia, ecoinovação, fotônica e sistemas embutidos para mobilidade e navegação, através da transversalidade e da diversificação relacionada* (related variety), criando assim novas configurações

* NT: O termo 'related variety' aplica-se ao contexto das aglomerações industriais e se refere, mais do que a uma economia diversificada, a uma economia que abarque atividades relacionadas em termos de competências que induzam a difusão do conhecimento. O conhecimento só se transfere de um setor para outro quando estes são complementares em ter- 
espaciais de empresas 'verdes' nas regiões. Cooke (2008) se refere a este tipo de agrupamento como 'agrupamento mutante jacobino', um processo evolutivo em regiões inovadoras caracterizadas por rápidos fluxos de conhecimento entre empreendedores cooperativos e instituições geradoras de conhecimento. Exemplos podem ser encontrados no norte e no sul da Califórnia (EUA), no norte de Jutland (Dinamarca), na região central de Israel e no País de Gales (Reino Unido).

Este paradigma do desenvolvimento não se baseia apenas na cooperação entre empresas para benefício econômico mútuo, mas também em ciclos fechados de materiais, via reciclagem, recuperação e reutilização de resíduos, bem como da promoção da ecoeficiência através da troca de diferentes subprodutos. Centra-se com frequência no conceito de parque ecoindustrial (Bristow e Wells, 2005).

A noção subjacente à concentração espacial dos empreendimentos em um parque industrial é a de que a proximidade dos negócios fortalece a competitividade das empresas nele inseridas e, consequentemente, da localidade. No entanto, as vantagens desta concentração nem sempre ficam evidentes em situações em que as empresas não possuem vínculos diretos entre si. Alguns acadêmicos também argumentam que os parques ecoindustriais não estão imbricados no contexto sociocultural. Como afirmam Wells e Bristow (2007), desenvolvimento regional ecoindustrialista sem um radical conteúdo social está estruturalmente condicionado a repetir os erros de épocas anteriores das políticas econômicas espaciais.

mos de competências compartilhadas. Assim, a "diversificação relacionada" é necessária para possibilitar vínculos efetivos. A "diversificação relacionada" é definida por Boschma e lammarino como o conjunto de "setores industriais interconectados em termos de competências compartilhadas ou complementares (definição de base cognitiva) (Boschma, R, lammarino, $\mathrm{S}$. Related variety and regional growth in Italy. Paper no 162. SPRU Electronic Working Paper Series. University of Sussex. September, 2007. Disponível em: <citeseerx.ist.psu.edu/viewdoc/ download?doi=10.1.1.144>. 
Isto é especialmente pertinente com relação à emergência do capitalismo verde, que tem sido criticado por ser 'nada menos do que uma ampla estratégia para a comodificação, mercantilização e financialização da ecologia, que intensifica e aprofunda radicalmente a penetração da natureza pelo capital' (Smith, 2007, p. 17). Assim, suas várias manifestações, tais como créditos de carbono e parques ecoindustriais, são vistas muitas vezes como perpetuadoras da mesma lógica neoliberal e da mesma rota de desenvolvimento, as quais são simplesmente renovadas com um leve tom verde (Bristow and Wells, 2005).

\section{Resiliência como uma alternativa ao conceito ecoeconômico no desenvolvimento rural}

Os exemplos descritos do setor agroalimentar e da inovação regional correm o risco de seguir ou ser levados a uma trajetória unidirecional de desenvolvimento econômico. A recente restrição creditícia global e o consequente aumento da insegurança relacionada à subsistência têm, contudo, dado destaque às vantagens de economias locais e regionais que apresentam maior 'resiliência' em virtude de serem menos dependentes de atividades globalmente desenraizadas, de contarem com maior diversidade econômica e/ou de estarem determinadas a priorizar e efetivar mudanças estruturais mais significativas (Larkin e Cooper, 2009; Ashby et al, 2009). Neste sentido, o discurso da resiliência vem atraindo crescente interesse nos círculos relacionados ao desenvolvimento regional, embora, como observam Christopherson e colegas (2010), em seu cerne esteja manifesto o desejo de responder à velha questão de por que algumas regiões logram superar as adversidades, sejam de curto ou de longo prazo, e manter uma boa qualidade de vida para seus habitantes e outras não. 
A hipótese é de que a integração entre diferentes formas de capital contribua para regiões mais resilientes. Ashby e colegas (2009) vêem a resiliência como a capacidade das regiões de experimentar ganhos econômicos positivos, o que é socialmente inclusivo, e operar dentro dos limites ambientais que podem conduzir a impactos econômicos globais (Ashby et al, 2009). Como tal, a resiliência converge nitidamente com a literatura sobre sustentabilidade, localização e diversificação e com o crescente entendimento das regiões como entidades intrinsecamente distintas, com trajetórias evolutivas e de desenvolvimento com contextos específicos (Hayter, 2004).

O significado de resiliência deriva em boa parte da forma como a palavra é utilizada nas ciências ecológicas. A resiliência pode ser vista como a capacidade de um sistema de absorver os distúrbios e reorganizar-se no decorrer de um processo de mudança interna, de modo a reter essencialmente a mesma função, estrutura e respostas (Hopkins, 2008, p. 54; Hudson, 2008). Este é, pois, um conceito holístico que vincula a análise de povos, instituições e economias com o contexto específico dos recursos naturais dos quais eles dependem fundamentalmente (Adger, 2000). Ele também está imbuído da noção de fechar, sempre que possível, os ciclos econômicos, 'estando mais preparados para um futuro mais ajustado, mais autosuficiente, e priorizando o local sobre o importado' (Hopkins, 2008, p. 55).

Bristow afirma que a ecoeconomia se expressa no nível regional; por exemplo, através de desenvolvimento do discurso da resiliência, da emergência do biorregionalismo e do desenvolvimento de movimentos de transição que busquem estabelecer mais firmemente a atividade econômica, em seus ambientes social e ecológico, em consonância com suas capacidades (Bristow, 2010). Localidades resilientes exigem diversidade, modularidade e devem ser caracterizados por uma ênfase 
na pequena escala, em atividades localizadas, que estejam embutidas nas capacidades do ambiente local, além de cientes dos seus limites e adaptadas aos mesmos (Bristow, 2010).

O discurso da resiliência se expressa na prática e evidencia suas características, por exemplo, no movimento de Comunidades de Transição. Este movimento busca estimular as comunidades a explorarem métodos para reduzir o uso de energia na era do pico do petróleo, bem como para ampliar sua autossuficiência econômica, política e social através de uma variedade de iniciativas locais.

Outro exemplo em que a resiliência se apresenta é no contexto do uso multifuncional da terra em iniciativas agroecológicas (ver, por exemplo, Van der Ploeg e Marsden, 2008). Muitas dessas iniciativas podem ser identificadas na América Latina, na África e na China. Estas expressões ecoeconômicas tratam os problemas ecológicos desenvolvendo práticas de agricultura que têm base local, portanto estão inseridas nas características do contexto local - físico, econômico e social -, utilizam recursos naturais de forma sustentável, estão enraizadas na experiência e na inovação dos agricultores e são mais resilientes por ampliarem suas bases de produção (Horlings e Marsden, 2011).

Se tais iniciativas podem ser disseminadas e, talvez o mais importante, se elas podem ser compatibilizadas com as relações sociais do capitalismo para efetivar um 'capitalismo verde' seguem sendo questões críticas.

\section{Conclusões: rumo a uma nova teorização do desenvolvimento rural/regional que incorpore a ecoeconomia no contexto da bioeconomia?}

Sustentamos, ao longo deste artigo, que tanto a bioeconomia como a ecoeconomia podem ser vistas como exemplos da teoria de moderni- 
zação ecológica; e que, aplicando o marco teórico da ME, podemos começar a desdobrar as diferenças radicais entre suas versões fraca (bioeconômica) e forte (ecoeconômica). Cada paradigma representa uma distinta variante da ME; a bioeconomia segue o caminho de uma ME fraca ou limitada, enquanto a ecoeconomia segue a linha forte da ME.

A bioeconomia como forma fraca de ME está enraizada em noções sobre a transformação da natureza pelo capital em 'segunda' natureza ou natureza social. Sugerimos que o paradigma bioeconômico vai muito além disto e começa a estabelecer uma 'terceira natureza'. Os processos bioeconômicos têm potencial para, e em alguns casos já conseguiram, transformar a natureza em um nível genético, fundamental. A bioeconomia tem uma posição firme nas grandes corporações agroalimentares; por exemplo, na produção de biocombustíveis, de biotecnologia e da genômica, no Brasil.

Estes novos avanços criam impactos, tais como apropriação internacional de terras, riscos imprevistos para as culturas resultantes de engenharia biológica e protestos sociais contra produção agrícola intensiva, em grande escala. Tanto o aumento da escala de produção como a miniaturização dos processos biológicos são uma expressão da desvinculação da produção agroalimentar de seu contexto ambiental e seus processos naturais. Apresentamos algumas dimensões perdidas - sociais, culturais, políticas e especiais - da ME fraca, neste contexto.

Os avanços da bioeconomia na inovação regional estão radicados nas noções de competitividade, de aglomerações de empresas e de fechamento dos ciclos de minerais, de água e de energia. Uma expressão para o nível regional é o parque ecoindustrial, que possibilita a inovação pela criação de redes interfirmas e de difusão de conhecimento. Estas expressões regionais da bioeconomia retratam as regiões primordialmente como parte de processos de globalização, como entidades econômicas competindo internacionalmente por trabalho e por recursos. Políticas ru- 
rais que favorecem expressões bioeconômicas enfatizam as variáveis chave de livre comércio, melhor estrutura para o transporte e a distribuição dos produtos e condições espaciais que estimulem a disseminação do conhecimento. Estas noções mostram, contudo, uma definição econômica demasiadamente limitada das regiões.

A bioeconomia é vista, cada vez mais, como uma panacéia multidimensional para a investida global da mudança climática, do crescimento populacional, da escassez de carbono e de alimentos (Horlings e Marsden, no prelo). Neste sentido, ainda que aqui possamos categorizar o paradigma como 'fraco ou forte', em termos de modernização ecológica ele tem influência política e econômica crescentes e detém potencial para um desenvolvimento espacial mais significativo, tanto no contexto rural como no urbano. Efetivamente, à medida que a concretização do pico do petróleo e do pico de alimentos se torna mais provável, ele adquire um maior impacto sobre os sistemas regionais de desenvolvimento. No entanto, a oposição ao mesmo também poderia crescer tanto que, talvez ironicamente, iria promover a coevolução da ecoeconomia. Como uma alternativa para a ME fraca, introduzimos o conceito mais abrangente de resiliência, que significa seguir 'a lógica dos lugares mais do que a lógica dos fluxos', que está incrustada nos recursos locais e nas redes sociais e que contribui para as iniciativas ecoeconômicas de base local. Exemplos desta são os vários modos de uso multifuncional da terra e as iniciativas agroecológicas, bem como o desenvolvimento de comunidades como no movimento 'Comunidades de Transição'.

A presente revisão crítica identificou alguns avanços emergentes relativos à modernização ecológica dos espaços rurais/regionais. Revisaramse aqui as principais correntes da literatura que começaram a rastrear os processos concorrentes da bioeconomia e da ecoeconomia. Uma questão chave é como estas contingências concorrentes entre a bioeconomia e a 
ecoeconomia irão se apresentar nos espaços rurais. Sustentamos que as discussões em curso precisam ser informadas pelos conceitos e debates contemplados neste artigo, especialmente, no que tange a como uma ecoeconomia de base rural mais vibrante pode ser estimulada por futuras políticas na América Latina.

\section{Towards sustainable spatial development? Exploring the implications of the emerging bio-economy in agri-food and regional innovation}

\section{Abstract}

The bio-economic paradigm can be described as those economic activities which capture the latent value in biological processes and renewable bioresources to produce improved health and sustainable growth and development. This article is a critical review of the impact of the emerging bio-economy in rural development. It describes some of its consequences in the sphere of agri-food and regional innovation based on a specific -and in our opinion weak - definition of Ecological Modernization. The central question then is: what are the conceptual roots, driving forces, empirical expressions and implications of bio-economic development? We argue that although the bio-economy makes severe sustainability claims, it also shows some missing links, has some negative environmental and social side-effects and runs the risk of a one-sided economy. We plead that the alternative trajectory of eco-economic development can be a serious alternative for especially vulnerable places, who want to increase their resilience.

Keywords: Sustainable development. Ecological Modernization. Bioeconomy. Eco-economy. Food production.

\section{Referências}

ADGER, N. Social and ecological resilience: are they related? Progress in Human Geography, Vol. 24, p. $347-64,2000$. 
ALTIERI, M. A.; ROSSET, P. The reasons why biotechnology will not ensure food security, protest the environment and reduce poverty in the developing world, AgBioForum, Vol.2, No. 3 \& 4, p. 155-162, 1999.

ANEX, R. Something new under the sun? The industrial ecology of biobased products. Journal of Industrial Ecology, Vol. 7, No. 3-4, p. 1-4, 2004.

ANDERSEN, M. S.; MASSA, I. Ecological modernization - Origins, dilemmas and future directions. Journal of Environmental Policy and Planning, Volume 2, Issue 4, 2000, p. 337-345, 2000.

ARMSTRONG, H.; TAYLOR, J. Regional economics and policy. 3rd Editon. London: Blackwell, 2000.

ASHBY, J. et al. An International Perspective of Local Government as Steward of Local Economic Resilience. Report by the Centre for Local Economic Strategies: Manchester, 2009.

BÖRJESSON, P. Good or bad bioethanol from a greenhouse gas perspective-what determines this? Applied Energy, 86, p. 589-594, 2009.

BRISTOW, G. Limits to regional competitiveness. In: TOMANEY, J. (ed.). The Future of Regional Policy. London: Smith Institute; Regional Studies Association, 2009.

BRISTOW, G. Resilient regions: re-'place'ing regional competitiveness. Cambridge Journal of Regions. Economy and Society, Vol. 3, No. 1, p. 153 - 167, 2010.

BRISTOW, G.; WELLS, P. Innovative discourse for sustainable local development: a critical analysis of eco-industrialism. International Journal of Innovation and Sustainable Development, Vol.1, No. 1/2, p. 168-179, 2005.

BUTTEL, F. H. Ecological modernization as social theory. Geoforum 31 (1), p. 57-65, 2000.

CARLSON, R. Laying the foundations for a bio-economy. Syst. Synth. Biology, Vol. 1, No. 3, p.109-117, August 2007.

CHRISTOFF, P. Ecological modernisation, ecological modernities. Environmental Politics, Vol. 5, Issue 3, p. 476 - 500, 1996.

CHRISTOPHERSON, S.; MICHIE, J.; TYLER, P. Regional resilience: theoretical and empirical perspectives. Cambridge Journal of Regions, Economy and Society, Vol. 3 (1), p. 3 - 10, 2010.

COOKE, P. Regional Innovation Systems, Clean Technology \& Jacobian ClusterPlatform Policies. Regional Science Policy \& Practice, Vol. 1., No.1, p. 23-45, 2008. 
DA SILVEIRA, J. M. F. J.; DE CARVALHO BORGES, I. An Overview of the current state of agricultural biotechnology in Brazil. University of Campinas, Paper presented at a workshop held at Bella Villagio, Bellagio, Italy, 2005.

DEUTZ, P.; GIBBS, D. Industrial Ecology and Regional Development: eco-Industrial development and cluster policy. Regional Studies, Vol. 42, No. 10, p. 13131328, 2008.

DRYZEK, J. S. The Politics of the Earth: environmental discourses. Oxford, UK: Oxford University Press, 1997.

DRUMMOND, I.; MARSDEN, T. K.; Regulating sustainable development. Global Environmental Change, 5, p. 51-64, 1995.

EUROPEAN COMMISSION (EC). New perspectives on the knowledge-based bio-economy. Science and Research Conference paper, EU, 2005.

EVANS, N. et al. Conceptualising agriculture: a critique of post-productivism as the new orthodoxy. Progress in Human Geography, 26, p. 313 -332, 2002.

GEELS, F. W. Understanding system innovations: a critical literature review and a conceptual synthesis. In: ELZEN, B.; GEELS, F. W.; GREEN, K. 2004 (eds.). System Innovation and the Transition to Sustainability. Cheltenham: Edward Elgar Publishing Ltd., 2004. p. 19-47.

GEELS, F. W. et al. Historische en hedendaagse systeem-innovaties in de glastuinbouw en varkenshouderij: een innovatie-sociologische analyse. Report, Zoetermeer: TransForum, 2008.

GIBBS, D. Ecological modernisation, regional economic development and regional development agencies, Vol., Issue 1, p. 9-19, 2000.

GOULDSON, A.; MURPHY, J. Ecological modernisation: restructuring industrial economies. In: JACOBS, M. (ed.). Greening the Millenium? The New Politics of the Environment. Oxford: Blackwell, 1997. p. 74-86.

GUTBERLET, J. Rural Development and Social Exclusion: a case study of sustainability and distributive issues in Brazil. Australian Geographer, Vol. 30, No. 2, 1 July 1999, p. 221-237(17), 1999.

HAJER, M. The politics of environmental discourse: ecological modernisation and the policy process. Oxford: Clarendon Press, 1995.

HARVEY, D. Spaces of Hope. Edinburgh: University of Edinburgh Press, 2000.

HAYTER, R. Economic geography as dissenting institutionalism: the embeddedness, evolution and differentiation of regions. Geografisker Annaler B, Vol 86, No.2, p. 95-115, 2004. 
HOPKINS, R. The Transition Handbook: from oil dependancy to local resilience. Chelsea: Green Books, 2008.

HORLINGS, I. Duurzaam boeren met beleid; innovatiegroepen in de Nederlandse landbouw. Dissertation, KUN, Nijmegen. Also published in Studies van Landbouw en Platteland no 20, Landbouw Universiteit, Wageningen, The Netherlands, 1996.

HORLINGS, I.; MARSDEN, T. (in press). Towards the real green revolution? Exploring the conceptual dimensions of a new ecological modernisation of agriculture that could 'feed the world'. Global Environmental Change. Disponível em: < doi:10.1016/j.gloenvcha.2011.01.004 >. Acesso em: 25 mai. 2011.

HUDSON, R. Towards sustainable economic practices, flows and spaces: or is the necessary impossible and the impossible necessary? Sustainable Development, Vol. 13, p. $239-252,2005$.

HUDSON, R. Material matters and the search for resilience: rethinking regional and urban development strategies in the context of global environmental change. International Journal of Innovation and Sustainable Development, Vol.3, No. 3/4, p. 166-184, 2008.

HUTTUNEN, S. Ecological modernisation and discourses on rural non-woord bioenergy production in Finland from 1980 to 2005. Journal of Rural Studies, 25, p. 239-247, 2009.

ISAAA. Global status of commercialized biotech/GM crops: 2008. ISAAA Briefs 39-2008. Disponível em:<http://www.isaaa.org >.

JÄNICKE, M. Ökologische Modernisierung. Optionen und Restriktionen Präventiver Umweltpolitik. In: SIMONIS, U. (ed.). Präventive Umweltpolitik. Frankfurt am Main: Campus, 1988. p.13-26.

JORDAN, N. et al. Sustainable development of the agricultural bio-economy. Science, Vol. 316, p. 1570-1571, 2007.

JUMA, C.; KONDE, V. The new bioeconomy: industrial and environmental biotechnology in developing countries. New York: United Nations Conference on Trade and Development, 2001.

KAUTSKY, K. Frederick Engels: his life, his work and his writings. Library of Progress, Kerr, No. 32, August 15, 1899.

KEIL, R. Sustaining modernity, modernizing nature: the environmental crisis and the survival of capitalism. In: KRUEGER, R.; GIBBS, D. (Eds.). The sustainable development paradox. London: Guilford, 2007. p. 41-65. 
KIRWAN, J. The interpersonal world of direct marketing: examining conventions of quality at UK farmers' markets. Journal of Rural Studies, Vol. 22, No. 3, p. 301-312, 2006.

KITCHEN, L.; MARSDEN, T. K. Creating sustainable rural development through stimulating the eco-economy: Beyond the eco-economic paradox? Sociologia Ruralis, Vol. 49, Issue 3, p. 273-294, 2009.

KITCHEN, L.; MARSDEN, T. K. (under review). Exploring the bio-economy and the ecological economy in spatial development.

LAMINE, C. Settling shared uncertainties: local partnerships between producers and consumers. Sociologia Ruralis, 45, p. 324-345, 2005.

LARKIN, K.; COOPER, M. Into recession: vulnerability and resilience in Leeds, Brighton, and Bristol. London: Centre for Cities, 2009.

MANN, S.; DICKENSON, J. Obstacles to the development of a capitalist agriculture. Journal of Peasant Studies, Vol. 5. No.4, p. 446-481, 1978.

MAYER, A. Material and energy use in Brazil 1970 - 2005, paper for the 15th ISSRM conference, Vienna, July 2009.

MARSDEN, T. The quest for ecological modernisation: re-spacing rural development and agri-food studies. Sociologia Ruralis, 44, p. 129 - 146, 2004.

MARSDEN, T. Mobilising the regional eco-economy: evolving webs of agri-food and rural development in the UK. Cambridge Journal of Regions, Economy and Society, p. 225-244, 2010.

MARSDEN, T.; MILBOURNE, P.; KITCHEN, L.; BISHOP, K. Communities in nature: the construction and understanding of forest natures. Sociologia Ruralis, 43, p. $238-256,2003$.

MARSDEN, T. K. (in press). Sustainability Science and a new spatial imagination. In: BLYTON, P.; FRANKLIN, A. (eds). Methodologies for Sustainability. Earthscan.

MCCARTHY, J. Rural geography: multifunctional geographies - reactionary or radical? Progress in Human Geography, Vol. 29, No. 6, p. 773-782, 2005.

MCCARTHY, J. Rural geography: alternative rural economies - the search for alterity in forests, fisheries, food, and fair trade. Progress in Human Geography, Vol. 30, No. 6, p. 803-811, 2006.

MEYNEN, W.; DOORNBOS, M. Decentralising natural resource management: a recipe for sustainability and equity? European Journal of Development Research, Vol. 16, No. 1, p. 235-254, 2004.

$\mathrm{MOL}, \mathrm{A}$. P. J. The environmental movement in an era of ecological modernization. Geoforum, Vol. 31, No. 1, p. 45-56, 2000. 
MOL, A. P. J.; SONNENFELD, D. A. Ecological Modernisation Around the World: perspectives and critical debates. London: Frank Cass Publishers, 2000.

MOL, A .P. J. Boundless biofuels. Between environmental sustainability and vulnerability. Sociologia Ruralis, 47 (4), p. 296-315, 2007.

MOMMAAS, H.; EWEG, R. Organizing Innovations and Transitions; Towards a more sustainable fit between innovation strategies and the institutional environment. In: VAN LATESTEIJN, H.; ANDEWEG, K. The TransForum Model: transforming agro innovation toward sustainable development. Springer, Dordrecht, Heidelberg, London, New York, 2011. p. 41-58.

MURPHY, J. Ecological modernization. Geoforum, Vol. 31, No.1, p. 1-8, 2000.

NILSSON, M. A. et al. A European Eco-Efficient Economy, Governing climate, energy and competitiveness. Report for the 2009 Swedish presidency of the Council of the European Union, Stockholm Environment Institute, Stockholm, Sweden, 2009.

OECD. The bioeconomy to 2030: designing a policy agenda. Paris, 2006.

PIKE, A. et al. Local and regional development. London: Routledge, 2006.

RFA. The Gallagher Review of the indirect effects of biofuels production. St. Leonards-On-Sea, Renewable Fuels Agency, 2008.

RENTING, H. et al. Understanding alternative food networks: exploring the role of short food supply chains in rural development. Environment and Planning A, 35, p. $393-411,2003$.

ROTMANS, J. et al. Duurzame ontwikkeling, van concept naar uitvoering. Maastricht: ICIS, Universiteit van Maastricht, 2001a.

ROTMANS, J. et al. More evolution than revolution: transition management in public policy. Foresight, 03 (01), p. 17, $2001 \mathrm{~b}$.

ROS, J. P. M. et al. Identifying the indirect effects of bio-energy production. Report of the Netherlands Environmental Assessment Agency, PBL, Bilthoven, 2010.

SMEETS, P. Expeditie Agroparken; Ontwerpend onderzoek naar metropolitane landbouw en duurzame ontwikkeling. Ph.D thesis Wageningen Universiteit, Wageningen, 2009.

SMITH, N. Uneven Development: nature, capital and the production of space. Oxford: Blackwell, 1984.

SMITH, N. Nature as Accumulation Strategy. Socialist Register, Vol. 43, 2007.

SPAARGAREN, G.; MOL, A. Sociology, environment and modernity: ecological modernization as a theory of social change. Society and Natural Resources, 5, p. 323-344, 1992. 
THE ROYAL SOCIETY. Reaping the benefits; Science and the sustainable intensification of global agriculture. London: The Royal Society, 2009.

VAN DER PLOEG, J.D.; MARSDEN, T. (eds.). Unfolding Webs; The Dynamics of regional rural development. Assen, The Netherlands: Royal van Gorcum, 2008.

WCED. Our Common Future. World Commission on Environment and Development. Oxford: Oxford University Press, 1987.

WELLS, P.; BRISTOW, G. Embedding eco-industrialism into local economies: the search for sustainable business and policy paradigms. Progress in Industrial Ecology-An International Journal, Vol. 4, No. 3-4, p. 205-218, 2007.

WHILE, A. et al. From sustainable development to carbon control: eco-state restructuring and the politics of urban and regional development. Transactions of the Institute of British Geographers, 35, p. 76-93, 2010.

WILSON, G. From productivism to post-productivism... and back again? Exploring the (un)changed natural and mental landscapes of European agriculture. Transactions of the Institute of British Geographers NS, 26, p. $77-102,2001$.

Recebido: 23/02/2011

Aceite final: 18/05/2011 
